Keywords: Mental Health, Primary health Care, United States.

\title{
Mental Health Problems in Primary Care: Progress in North America
}

\author{
Kathryn M. Magruder, M.P.H., Ph.D.*,** \\ Derik E. Yeager, M.B.S.** \\ * Mental Health Service, Veterans Affairs \\ Medical Center, 109 Bee Street, \\ Charleston, SC 29401-5799 \\ ** Department of Psychiatry and Behavioral \\ Sciences and Department of Biostatistics, \\ Bioinformatics and Epidemiology, Medical \\ University of South Carolina, Charleston, \\ SC 29425
}

USA

\begin{abstract}
Background and Objectives: Research in the last decade has acknowledged that primary care plays a pivotal role in the delivery of mental health services. The aim of this paper is to review major accomplishments, emerging trends, and continuing gaps concerning mental health problems in primary care in North America.

Methods: Literature from North America was reviewed and synthesized.

Results: Major accomplishments include: the development and adoption of a number of clinical guidelines specifically for mental health conditions in primary care, the acceptance of the chronic care model as a framework for treating depression in primary care, and the clear adoption of pharmacologic approaches as the predominant mode for treating depression and anxiety. Emerging trends include: the use of non-physician facilitators as care managers in the treatment of depression in primary care, increasing use of technology in the assessment and treatment of mental health conditions in primary care, and dissemination and implementation of integrated mental health treatment approaches. Lingering issues include: the difficulty in moving beyond problem identification and initiation of treatment to sustaining evidence-based treatments, agreement on a common metric to evaluate outcomes, and the stigma still associated with mental illness.

Conclusion: Though there now exists a solid and growing evidence base for the delivery of mental health services in primary care, there are still significant challenges which must be overcome in order to make further advances.
\end{abstract}


The last decade has seen considerable progress in North America in both practice and research regarding mental health problems in primary care. This is evident in a number of evidence-based practice patterns that have been implemented and that reflect an integrated approach to providing mental health care in the primary care setting. As well, there are emerging trends which build on this increasingly solid evidence base. Despite significant gains, there are still some issues which should be resolved in order for the most patients to receive the full benefit of treating mental health problems in primary care. This paper summarizes the accomplishments of the past decade, emerging trends which will likely be influential in the provision of care in the coming decade, and lingering challenges.

\section{Major Accomplishments}

Important milestones in the past decade are reflected in a number of ways, but can be summarized by a few major accomplishments and trends. In general, these areas reflect consolidation and vetting of considerable research evidence. Major successes have been with screening and treatment initiation.

Illustrative of this are the screening recommendations by the United States Preventive Health Task Force ${ }^{1}$. These recommendations are largely oriented to the prevention of common primary care medical conditions and are "graded" based on the quality of supporting research evidence. In the 1996 $2^{\text {nd }}$ edition of the Guide to Clinical Preventive Services, six mental health conditions were considered (dementia, depression, suicide risk, family violence, problem drinking, and drug abuse); problem drinking was the only condition with a recommendation for screening. As of this writing, only depression has been added to the list, based largely on new studies that demonstrate treatment effectiveness in primary care ${ }^{2,3}$; nevertheless, this addition reflects advances in research and a major shift in thinking from prior editions and presages recommendations for other mental conditions in primary care (e.g., post-traumatic stress disorder, or PTSD).

There are now several clinical practice guidelines, based on research evidence and expert consensus, which have been developed specifically for mental health problems in primary care. These include VA/DoD guidelines for the assessment and treatment of major depression (MDD), PTSD, and substance use disorders ${ }^{4}$, as well as AHCPR/ AHRQ guidelines for MDD ${ }^{5}$ and attention deficit/hyperactivity disorder ${ }^{6,7}$. The development of these guidelines and their growing acceptance demonstrate that it is possible to address effectively some common mental health conditions in primary care.

Another clear advance has been the development and acceptance of the chronic care model ${ }^{8,9}$. Borne out of concern that traditional primary care is more oriented to acute illness and that a major overhaul of primary care is necessary in order to respond to chronic illness (which constitutes the major focus of primary care practice), the chronic care model (and its variations) has focused on six inter-related aspects of primary care: self-management support, clinical information systems, delivery system redesign, decision support, health care organization, and community resources. It has proven to be a good structure for improving treatment of depression. This multi-faceted approach, with heavy emphasis on specialty collaboration, patient education, self-monitoring, and frequent follow-up (by trained 
nurses) as adjunctive components to pharmacologic treatment, has been successful in multiple venues ${ }^{10,11}$. The success of this model is largely due to the fact that depression is approached similarly to other chronic illnesses for which primary care providers have responsibility, and the system is designed to support chronic disease management. This model has helped to integrate successfully depression treatment strategies in primary care settings.

In the last decade, pharmacologic treatment of has become the norm for treatment of depression ${ }^{12}$. Given the ease with which these medications can be prescribed (low abuse potential, few side effects, easy dosing schedules), antidepressant use in primary care has dramatically increased from $2.6 \%$ of visits in 1989 to $7.1 \%$ of visits in $2000^{13}$. This has driven an increase in rates of treatment for depression -- particularly in the general medical sector where rates of treatment were 2.59 times higher between 1990-92 and 2001-03 ${ }^{14}$. Because the primary care sector is so large, the increase in treatment rates translates into an overall population increase in treatment and access to care. Primary care providers are thus diagnosing a higher percentage of their caseload with a mental disorder ${ }^{15}$. Trends are similar for the treatment of attention deficit/hyperactivity disorder (ADHD) ${ }^{16}$.

\section{Emerging Trends}

With the consolidation of therapeutic evidence and primary care organizational and delivery models, a major challenge is expeditious implementation. Cross-training nurses and other health professionals using technology-assisted screening, diagnosis, and follow-up tools, and using the internet in therapy and follow-up are some of the trends that are apt to take hold in the coming decade.

Technological advances have improved the way medical professionals retrieve information (electronic medical records, handheld computers) while also improving interaction and communication with patients (telephones, cellular telephones, email, and internet) for the purpose of screening, diagnosing, and monitoring mental health disorders. As patients and providers become more comfortable with these technologies, and the research base builds demonstrating at least equivalent effectiveness compared to "usual" operations, we can expect to see increased use of such technologies in the management of mental health problems in primary care. For example, electronic medical records can provide easy access to comprehensive medical notes as well as feedback and treatment options for clinicians. Feedback such as clinical reminders and treatment recommendations can be generated offsite or delivered immediately in the form of computer-generated treatment prompts in order to improve initial management of depression in primary care ${ }^{17}$.

More use of the telephone to conduct initial mental health screens as well as treatment follow-up can prove efficient as well as expand treatment options for those who live in rural areas or do not have access to computers or web-based assessments and/or treatments. While the use of this technology in other areas of health care is well established ${ }^{18}$, its application in the area of mental health is burgeoning. See, for example, the study by Simon et al. ${ }^{19}$, which showed improved depression outcomes following a telephone-delivered protocol that included feedback coupled with care management, that by Hunkeler et al. ${ }^{20}$ which demonstrated improvement in depression with nurse 
tele-health care and peer support, and that by Dietrich et al. ${ }^{21}$ which showed improved treatment response with supervised telephone support.

Many screeners and diagnostic assessments, such as the Primary Care Evaluation of Mental Disorder or PRIME-MD ${ }^{22,23}$, that have been developed specifically for use in primary care settings have since been adapted for computer-administration. Other, more recent tools, such as the Drug Abuse Problem Assessment for Primary Care or DAPA$\mathrm{PC}^{24}$, were designed specifically to be administered via computer. While currently popular in the areas of depression and substance abuse, the audience for assessment tools is expanding for a number of reasons, including: convenience, privacy, high patient satisfaction $^{23}$, decreased provider time, improved validity and reliability ${ }^{25}$, and decreased expense. As patients become more familiar with inputting medical information on computers, this technology may eventually replace standard mental health assessment practice.

Even more exciting is the use of the Internet as both a supplemental and an independent treatment modality. Web-based behavioral treatment is gaining favor among practitioners $^{26}$ and may benefit patients who may not otherwise seek or receive treatment ${ }^{27}$. The efficacy of using the Internet as a self-management tool for military veterans in primary care with PTSD is currently under investigation in a randomized trial funded by the National Institute of Mental Health $^{28}$ and the Department of Defense (study number not yet assigned). Given the current utility of the Internet as a tool for providing evidence-based treatment for depression $^{29}$ and PTSD ${ }^{30,31}$ and the fact that it is one of the first places that many people turn to learn about symptoms and health conditions, it is likely to emerge as a dominant health care trend in future decades.

While the integration of technology into primary care has the potential to improve quality of care for mental health conditions, technology alone is insufficient. The use of trained nurses or psychologists as care managers to augment medical therapeutics has been shown to be effective in terms of depressive symptomotology $y^{32-34}$. Given the time involved in patient education and follow-up, such individuals will almost certainly be a part of any primary care team that expects to manage mental health problems successfully and efficiently.

Several large scale studies have demonstrated that it is feasible to disseminate depression management programs into primary care practice with resultant improved outcomes $^{21,32-34}$. Sustainability and implementation under non-research conditions may prove more difficult, as these programs typically increase costs of care ${ }^{35}$. Combining such programs with technological innovations (e.g., computerized screening, telephone follow-up) as is currently being done with the Translating Initiatives for Depression into Effective Solutions program ${ }^{36}$ of the U.S. Veterans Administration may help to improve the cost to benefit ratio. Furthermore, as technology improves (as well as patient and provider comfort levels), we can expect to see better integration of technology into depression care management packages with resultant cost reductions.

\section{Challenges}

Despite the gains made in the past decade, there are still some hurdles to overcome. A challenge for researchers is to develop a bet- 
ter system for benchmarking mental health outcomes in primary care. The National Committee for Quality Assurance (NCQA) uses the Health Plan Employer Data and Information Set (HEDIS) as a set of standardized performance measures to provide performance information on managed health care plans to consumers and purchasers ${ }^{37}$. This widely respected system currently relies on process measures (e.g., presence, duration, and dosing of anti-depressant prescription; number and timing of follow-up visits), whereas in other areas of medicine it is possible to measure medical outcomes (e.g., blood pressure, $\mathrm{HgA1c}$ ). Thus, a major challenge for this field is to agree on a measure that reflects outcomes that have been tied to successful interventions.

While improvements have been made in rates of treatment of mental health problems in primary care ${ }^{14}$, a persistent challenge remains the number of patients in primary care with mental disorders who do not receive treatment. Approximately 50\% of those who could benefit from treatment still go untreated ${ }^{38,39}$, and even fewer receive adequate treatment ${ }^{39}$. The reasons are multifactorial, including: stigma ${ }^{40,41}$, inadequate systems to support treatment decisions ${ }^{11}$, inadequate mental health benefits ${ }^{42}$, and inadequate training of providers for longterm treatment ${ }^{43}$.

\section{Conclusion}

Significant gains in treating mental health problems in primary care have been primarily in the areas of screening and treatment initiation. While effective structures have been developed to support effective mental health treatment in primary care, their widespread implementation and adoption may be hindered by cost issues. As technological advances gain acceptance, we can expect reduced costs and increased integration of treatment approaches while potentially reducing stigma. As treatments and technology continue to improve, we can expect considerable advances in the treatment of mental health problems in primary care.

\section{References}

1. U.S. Preventive Services Task Force. Guide to Clinical Preventive Services, Second Edition. Baltimore, MD: Williams \& Wilkins, 1996.

2. Guide to Clinical Preventive Services, 2006. AHRQ Publication No. 06-0588, June 2006. Agency for Healthcare Research and Quality, Rockville, MD. http://www.ahrq.gov/ clinic/pocketgd.htm

3. Pignone MP, Gaynes BN, Rushton JL, Burchell CM, Orleans CT, Mulrow CD. Screening for depression in adults: a summary of the evidence for the U.S. Preventive Services Task Force. Ann Intern Med 2002; 136(10): 765-776.

4. VA/DoD Clinical Practice Guidelines, Washington, DC: Office of Quality and Performance, Department of Veterans Affairs. [updated 2006 Sept 11]. Available from: http://www.oqp.med.va.gov/cpg/cpg.htm

5. Schulberg H, Katon W, Simon G, Rush A. Treating major depression in primary care practice: an update of the AHCPR practice guidelines. Arch Gen Psychiatry 1998; 55: 1121-1127.

6. American Academy of Pediatrics. Clinical practice guidelines: diagnosis and evaluation of children with attention-deficit/hyperactivity disorder. Pediatrics 2000; 105 : 1158-1170.

7. American Academy of Pediatrics. Clinical practice guidelines: treatment of the school aged child with attention-deficit/hyperactivity disorder. Pediatrics 2001; 108: 1033-1044.

8. Wagner EH. Chronic disease management: What will it take to improve care for chronic illness? Eff Clin Pract 1998; 1: 2-4.

9. Bodenheimer T, Wagner EH, Grumbach K. Improving primary care for patients with chronic illness. JAMA 2002; 288(14): 1775-1779. 
10. Katon W, Von Korff M, Lin E, Walker E, Simon GE, Bush $\mathrm{T}$ et al. Collaborative management to achieve treatment guidelines. Impact on depression in primary care. JAMA 1995; 273(13): 1026-1031.

11. Rost K, Nutting P, Smith J, Werner J, Duan N. Improving depression outcomes in community primary care practice. J Gen Intern MedJournal of General Internal Medicine 2001; 16: 143-149.

12. Olfson M, Marcus SC, Druss B, Elinson L, Tanielian, T, Pincus HA. National trends in the outpatient treatment of depression. JAMA 2002; 287: 203-209.

13. Pirraglia PA, Stafford RS, Singer DE. Trends in prescribing of selective serotonin reuptake inhibitors and other newer antidepressant agents in adult primary care. Prim Care Companion J Clin PsychiatryPrimary Care Companion Journal of Clinical Psychiatry 2003; 5: 153157.

14. Kessler RC, Demler O, Frank RG, Olfson M, Pincus HA, Walters EE et al. Prevalence and treatment of mental disorders, 1990 to 2003. N Engl J Med 2005; 352(24): 2515-2523.

15. Druss BG, Bornemann T, Fry-Johnson YW, McCombs HG, Politzer RM, Rust G. Trends in Mental Health and Substance Abuse Services at the Nation's Community Health Centers: 1998-2003. Am J Public Health 2006; 96: 1779-1784.

16. Olfson M, Gameroff MJ, Marcus SC, Jensen PS. National trends in the treatment of attention deficit hyperactivity disorder. Am J Psychiatry 2003; 160: 1071-1077.

17. Rollman B, Hanusa B, Gilbert T, Lowe H, Kapoor W, Schulberg H. The electronic medical record. Arch Intern Med 2001; 22: 189-197.

18. Litzelman D, Dittus R, Miller M, Tierney WM. Requiring physicians to respond to computerized reminders improves their compliance with preventative care protocols. J Gen Intern Med 1993; 8: 311-317.

19. Simon GE, Von Korff M, Rutter C, Wagner E. Randomised trial of monitoring, feedback, and management of care by telephone to improve depression treatment in primary care. Br Med J 2000; 320: 550-554.

20. Hunkeler EM, Meresman JF, Hargreaves WA, Fireman B, Berman WH, Kirsch AJ et al. Efficacy of nurse telehealth care and peer support in augmenting treatment of depression in primary care. Arch Fam Med 2000 Aug; 9(8): 700-708.

21. Dietrich AJ, Oxman TE, Williams JW Jr, Schulberg HC, Bruce ML, Lee PW et al. Re-engineering systems for the treatment of depression in primary care: cluster randomised controlled trial. BMJ 2004; 329(7466): 602.
22. Spitzer RL, Kroenke K, Williams JB. Validation and utility of a self-report version of PRIME-MD. JAMA 1999; 282: 1737-1744.

23. Kobak KA, Taylor LH, Dottl SL, Greist JH, Jefferson JW, Burroughs D et al. A computer-administered telephone interview to identify mental disorders. JAMA 1997; 278(11): 905-910.

24. Holtz K, Landis RD, Nemes S, Hoffman J. DAPAPC: development of a computerized screening system to identify substance abuse in primary care. J Healthc Qual 2001; 23(3): 34-37.

25. Greist JH. Clinical Computing: The computer as clinician assistant: assessment made simple. Psychiatr Serv 1998; 49: 467-472.

26. Ritterband LM, Gonder-Frederick LA, Cox DJ, Clifton AD, West RW, Borowitz SM. Internet interventions: In review, in use, and into the future. Prof Psychol Res Pr 2003; 34: 527-534.

27. Gustafson DH, Hawkins R, Boberg E, Pingree S, Serlin RE, Graziano F et al. Impact of a patient-centered, computer-based health information/support system. Am J Prev Med 1999; 16(1): 1-9.

28. NIMH Study Number: NGA: 1 R34 MH078874-01. Randomized Trial of an Online Early Intervention for Combat PTSD in Primary Care, 2007. PI: Engel CC.

29. Christensen H, Griffiths KM, Korten A. Web-based cognitive behavior therapy: analysis of site usage and changes in depression and anxiety scores. J Med Internet Res 2002; 4(1): e3.

30. Lange A, Rietdijk D, Hudcovicova M, van de Ven JP, Schrieken B, Emmelkamp PM. Interapy: a controlled randomized trial of the standardized treatment of posttraumatic stress through the internet. J Consult Clin Psychol 2003; 71: 901-909.

31. Litz BT, Williams L, Wang J, Bryant R, Engel CC. A Therapist-Assisted Internet Self-Help Program for Traumatic Stress. Prof Psychol Res Pr 2004; 35(6): 628-634.

32. Wells KB, Sherbourne C, Schoenbaum M, Duan N, Meredith L, Unützer J, et al. Impact of Disseminating Quality Improvement Programs for Depression in Managed Primary Care: A Randomized Controlled Trial. JAMA 2000; 283: 212-220.

33. Unutzer J, Katon W, Callahan CM, Williams JW Jr, Hunkeler E, Harpole L et al. Collaborative care management of late-life depression in the primary care setting: a randomized controlled trial. JAMA 2002; 288(22): 28362845 .

34. Bruce ML, Ten Have TR, Reynolds CF 3rd. Katz II, Schulberg HC, Mulsant BH et al. Reducing suicidal idea- 
tion and depressive symptoms in depressed older primary care patients: a randomized controlled trial. JAMA 2004; 291(9): 1081-1091.

35. Neumeyer-Gromen A, Lampert T, Stark K, Kallischnigg $\mathrm{G}$. Disease management programs for depression: a systematic review and meta-analysis of randomized controlled trials. Med Care 2004; 42(12): 1211-1221.

36. VA/HSR\&D Study Number: MNT 03-215. Expanding and Testing VA Collaborative Care Models for Depression, 2004. PI: Rubenstein LV. Available at: http://www.hsrd.research.va.gov/research/abstracts.cfm?P roject_ID=2141693963

37. 2000 National Committee for Quality Assurance. HEDIS Technical Specifications, Vol 2. Washington DC: National Committee for Quality Assurance; 1999; pp. 105-110.

38. Magruder KM, Frueh BC, Knapp RG, Davis L, Hamner MB, Martin RH et al. Prevalence of posttraumatic stress disorder in Veterans Affairs primary care clinics. Gen Hosp Psychiatry 2005; 27: 169-179.

39. Wang PS, Berglund P, Kessler RC. Recent care of common mental disorders in the United States: prevalence and conformance with evidence-based recommendations. J Gen Intern Med 2000; 15: 284-292.
40. Hinshaw SP, Cicchetti D. Stigma and mental disorder: Conceptions of illness, public attitudes, personal disclosure, and social policy. Dev Psychopathol 2000; 12: 555-598.

41. Hoge CW, Castro CA, Messer SC, McGurk D, Cotting DI, Koffman RL. Combat duty in Iraq and Afghanistan, mental health problems, and barriers to care. N Engl J Med 2004; 351: 13-22.

42. Barry CL, Gabel JR, Frank RG, Hawkins S, Whitmore HH, Pickreign JD. Design of mental health benefits: still unequal after all these years. Health Aff 2003; 22(5): 127-137.

43. Williams J, Rost K, Dietrich A, Ciotti M, Zyzanski S, Cornell J. Primary care physicians' approach to depressive disorders: effects of physician specialty and practice structure. Arch Fam Med 1999; 8: 58-67.

Address for correspondence:

Kathryn M. Magruder, PhD, MPH

Ralph H. Johnson VA Medical Center

109 Bee Street, Charleston, SC 29425

Phone: (843) 789-7280

FAX: (843) 937-6100

Email: magrudkm@musc.edu 


\section{Linguistics \& Language Behavior Abstracts}

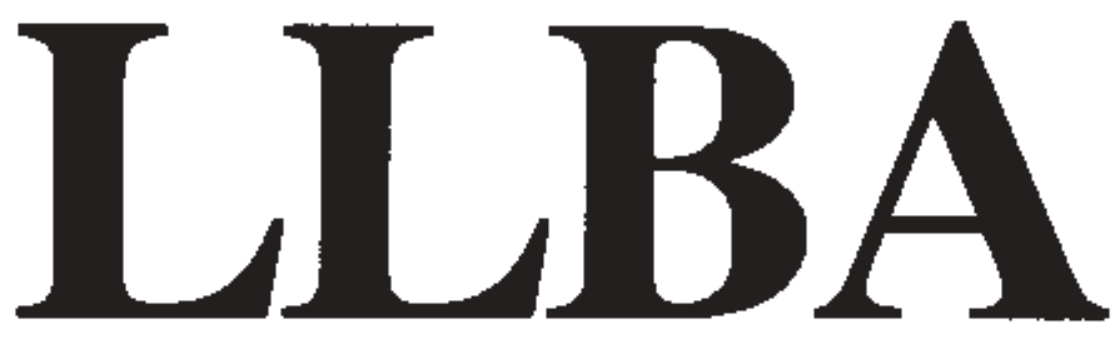

Now entering our 26 th year $(135,000$ abstracts to date) of service to linguists and language researchers worldwide. LLBA is available in print and also online from BRS and Dialog.

Linguistics \& Language Behavior Abstracts

$$
\text { P.O. Box } 22206
$$

San Diego. CA 92192-0206

Phone [619] 695-8803 FAX 1619) 695-0416

Fast, economical document delivery ovailable. 